\title{
Uji Performa Citra Worldview 3 dan Sentinel 2A untuk Pemetaan Kedalaman Laut Dangkal (Studi Kasus di Kepulauan Karimunjawa, Jawa Tengah)
}

\author{
Image Performance Test on Worldview 3 and Sentinel 2A for Mapping Shallow Water Depth \\ (Case Study in Karimunjawa Islands, Central Java)
}

\begin{abstract}
Luhur Moekti Prayogo', Abdul Basith²
1Magister Teknik Geomatika Departemen Teknik Geodesi, Fakultas Teknik, Universitas Gadjah Mada, Yogyakarta, Indonesia ${ }^{2}$ Departemen Teknik Geodesi, Fakultas Teknik, Universitas Gadjah Mada, Yogyakarta, Indonesia
\end{abstract}

Penulis Korespondensi: Abdul Basith | Email: abd_basith@ugm.ac.id

Diterima (Received): 07/09/2020 Direvisi (Revised): 13/11/2020 Diterima untuk Publikasi (Accepted): 14/11/2020

\begin{abstract}
ABSTRAK
Satellite-Derived Bathymetry (SDB) merupakan salah satu teknik dalam penginderaan jauh untuk penyediaan data kedalaman perairan dangkal menggunakan citra satelit. Pada citra, kisaran panjang gelombang 450 hingga 580 nm memiliki kemampuan menembus perairan dengan cukup baik dibandingkan dengan panjang gelombang yang lain. Penelitian ini bertujuan untuk mengetahui pengaruh resolusi spasial dalam estimasi kedalaman khususnya dengan algoritma Stumpf menggunakan panjang gelombang tampak. Studi ini dilakukan menggunakan citra Worldview 3 dan Sentinel 2A di Kepulauan Karimunjawa, Jawa Tengah. Hasil dari penelitian ini menunjukkan bahwa model kedalaman terbaik pada citra Worldview 3 dan Sentinel 2A yaitu dengan nilai $y=0,8847 x+0,2204$ dan $R^{2}$ sebesar 0,7135 dan $y=0,858 x+0,3123$ dan $R^{2}$ sebesar 0,6974 . Panjang gelombang tampak dengan band ratio Hijau-Biru pada citra Worldview 3 dan Sentinel 2A menghasilkan kedalaman terbaik pada rentang kedalaman 0-5 m yang ditunjukkan dengan nilai RMSE sebesar 1,526 dan 1,558 m. Dari penelitian ini, dapat disimpulkan bahwa citra satelit resolusi tinggi menghasilkan nilai RMSE yang cenderung lebih kecil dibandingkan dengan citra resolusi sedang.
\end{abstract}

Kata Kunci: SDB, Stumpf, Band Ratio, Pemetaan, Karimunjawa

\section{ABSTRACT}

Satellite-Derived Bathymetry (SDB) is a remote sensing technique for providing shallow water depth using satellite imagery. The wavelength range of 450 to $580 \mathrm{~nm}$ has a reasonably good water capability than other wavelengths in the image. This study aims to determine the effect of spatial resolution in-depth estimation, especially with the Stumpf algorithm using visible wavelengths. This study was conducted using Worldview 3 and Sentinel 2A imagery in the Karimunjawa Islands, Central Java. The results of this study indicate that the best depth model is the Worldview 3 and Sentinel $2 A$ imagery with a value $y=0,8847 x+0,2204$ and $R 2=0,7135$ and $y=0,858 x+$ 0,3123 and $R 2=0,6974$. The visible wavelength with the Green-Blue band ratio on the Worldview 3 and Sentinel $2 A$ imagery produces the best depth in the 0-5 $\mathrm{m}$ depth range as indicated by the RMSE values of 1,526 1,558 $\mathrm{m}$. From this research, it can be concluded that highresolution satellite images produce RMSE values, which tend to be smaller than medium resolution images.

Keywords: SDB, Stumpf, Band Ratio, Mapping, Karimunjawa

(C) Author(s) 2020. This is an open access article under the Creative Commons Attribution-ShareAlike 4.0 International License (CC BY-SA 4.0).

\section{Pendahuluan}

Keberadaan data batimetri merupakan salah satu aspek yang sangat penting dalam pengelolaan lingkungan laut (Nuha dkk, 2019). Pusat Hidrografi dan Oseanografi
TNI Angkatan Laut (Pushidrosal) merupakan lembaga yang mempunyai kewenangan dalam pengadaan data hidrografi termasuk didalamnya Batimetri. Lembaga ini bertanggungjawab dalam penyediaan data dan informasi hidro-oseanografi untuk berbagai kepentingan (Pusat 
Hidrografi dan Oseanografi Angkatan Laut, 2016). Pada umumnya, perolehan data batimetri dilakukan dengan menggunakan metode konvensional dan terestris. Namun kedua metode tersebut membutuhkan waktu yang relatif lama, biaya yang cukup mahal, terbatas pada beberapa area yang tidak dapat dijangkau kapal survei dan khusus pada metode konvensional terbatas pada kedalaman $<25$ m (Arya dkk, 2016; Nuha dkk, 2019). Oleh karena itu perlu adanya alternatif baru dalam pengadaan data kedalaman perairan.

Dewasa ini, perkembangan teknologi terjadi dalam berbagai bidang, salah satunya penginderaan jauh. Perkembangan ini ditandai dengan ketersediaan citra resolusi tinggi seperti citra Worldview 3 dengan resolusi $31 \mathrm{~cm}$ pada band pankromatik dan $1,24 \mathrm{~m}$ pada band multispektral (Digital Globe, 2014). Tidak hanya itu, citra dengan resolusi sedang open source (gratis) juga banyak tersedia salah satunya citra Sentinel 2A dengan resolusi spasial $10 \mathrm{~m}$ (Satellite Imaging Corporation, 2017). Kedua tipe ini memiliki kelebihan diantaranya revisit time yang cukup tinggi dan kanal spektral yang cukup lengkap yang dapat digunakan dalam berbagai keperluan seperti analisis biomassa dan pemetaan sumberdaya (Santosa, 2016; Bakara, 2014).

Selain memiliki resolusi spasial yang berbeda, kedua citra ini memiliki band tampak yaitu Merah, Hijau dan Biru. Setiap band memiliki panjang gelombang yang berbeda dimana kombinasi dari band tersebut dapat digunakan dalam berbagai analisis. Berdasarkan informasi dari Satellite Imaging Corporation (2020) citra Worldview 3 band tampak memiliki panjang gelombang diantaranya Merah: 630 - 690 nm, Hijau: 510 - $580 \mathrm{~nm}$ dan Biru: 450 $510 \mathrm{~nm}$. Sedangkan pada citra Sentinel 2A, band tampak multispektral memiliki panjang gelombang yaitu Merah $665 \mathrm{~nm}$, Hijau: $560 \mathrm{~nm}$ dan Biru: $490 \mathrm{~nm}$ (Satellite Imaging Corporation, 2017). Menurut Wicaksono (2015) penggunaan band tampak khususnya dengan band ratio Hijau-Biru memiliki kemampuan dalam menembus perairan dengan cukup baik dibandingkan dengan band yang lain. Tidak hanya itu, Wicaksono (2015) juga mengatakan bahwa salah satu kelebihan penggunaan band ratio yaitu dapat mereduksi tutupan dasar perairan yang heterogen pada analisis Satellite-Derived Bathymetry (SDB).

Satellite-Derived Bathymetry (SDB) merupakan teknik dalam bidang penginderaan jauh yang memanfaatkan data citra satelit untuk perolehan informasi kedalaman perairan (Nuha, 2019). Terdapat dua metode dalam teknik SDB, yaitu Analitis dan Empiris (Lyzenga, 1978; Gao, 2009). Metode Analitis merupakan perolehan informasi kedalaman yang menggunakan prinsip penetrasi cahaya dalam air dan membutuhkan sifat optis air seperti koefisien absorpsi, koefisien atenuasi, koefisien hamburan dan reflektansi dasar (Nuha dkk, 2019). Selanjutnya, metode Empiris dengan prinsip menghubungkan nilai spektral citra dengan kedalaman terukur (Syaiful dkk, 2019). Metode ini lebih mudah dan praktis dalam praktiknya dikarenakan tidak memperhatikan bagaimana gelombang elektromagnetik yang dipancarkan dari satelit merambat dalam air (Gao, 2009). Salah satu algoritma derivasi kedalaman pada metode Empiris yang masih cukup jarang untuk dikaji adalah Algoritma Stumpf (Stumpf dkk, 2003).

Stumpf merupakan algoritma SDB yang menggunakan band ratio dalam operasinya (Stumpf dkk, 2003). Menurut Irwanto (2018), penggunaan band ratio dapat melihat hubungan antara kedalaman dengan tingkat penyerapan setiap band. Hal ini dapat diartikan bahwa jika kedalaman perairan terus bertambah, band dengan tingkat penyerapan tinggi akan terus berkurang. Hal ini dibuktikan dengan penelitian Wicaksono (2015) yang dilakukan di perairan Kemujan, Jawa Tengah untuk menguji band ratio dan band tunggal menggunakan citra resolusi tinggi Worldview 2 dengan metode LogTransformed (Empiris). Penelitian tersebut menghasilkan bahwa band ratio mampu mereduksi tutupan dasar yang heterogen dibandingkan dengan band tunggal. Kemudian penelitian Pajrin (2018) menggunakan algoritma Jupp (Empiris) pada citra Sentinel 2A yang menghasilkan overall accuracy sebesar $81.11 \%$ dengan total nilai kedalaman overestimate sebesar $84 \%$ dan underestimate sebesar 16\%. Selanjutnya penelitian Bobsaid dan Jaelani (2017) menggunakan dua citra yaitu citra Landsat 8 dan Sentinel 2A menggunakan metode Empiris. Pada Landsat 8 menghasilkan Normalized Mean Absolute Error (NMAE) sebesar 25,777\%, sedangkan pada citra Sentinel 2A menghasilkan NMAE 26,887\%.

Dari penelitian diatas dapat diketahui bahwa keberadaan citra resolusi tinggi dan sedang menjadi kajian cukup menarik untuk pengadaan data kedalaman perairan dangkal. Band tampak yang dimiliki setiap citra akan menggambarkan performa dalam estimasi kedalaman yang kemungkinan resolusi spasial citra akan mempengaruhi hasil estimasi. Oleh karena itu, tujuan dari penelitian ini adalah membandingkan citra Worldview 3 dan Sentinel 2A dalam estimasi kedalaman perairan dangkal di Kepulauan Karimunjawa, Jawa Tengah. Lokasi ini dipilih karena memiliki kondisi perairan dangkal dengan pertimbangan keterbatasan gelombang elektromagnetik dalam menembus perairan.

\section{Bahan dan Lokasi Penelitian}

Bab ini menjelaskan mengenai bahan dan lokasi penelitian.

\section{a. Bahan Penelitian}

Citra pertama yang digunakan dalam penelitian ini adalah citra resolusi tinggi (Worldview 3) dengan band Merah, Hijau, Biru dan Near Infrared (NIR) yang sudah terkoreksi radiometrik. Koreksi ini dilakukan oleh pihak Digital Globe dengan algoritma DigitalGlobe's Atmospheric Compensation (ACOMP) (Digital Globe, 2016). Citra kedua yaitu Sentinel 2A yang merupakan citra resolusi sedang (United States Geological Survey, 2015). Citra ini belum terkoreksi radiometrik sehingga perlu dilakukan koreksi radiometrik terlebih dahulu sebelum dilakukan pemrosesan. 
Perbandingan kedua citra dalam penelitian ini juga mempertimbangkan waktu akuisisi citra yang bertujuan agar kondisi obyek yang diamati tidak berbeda jauh antara citra satu dengan yang lain. Kedua citra ini memiliki waktu akuisisi yang sama yaitu pada bulan Februari 2018. Kemudian pengukuran data kedalaman in-situ menggunakan Single Beam Echosounder (SBES) Bathy2010 SyQwest yang dilakukan pada 20-23 Maret 2019. Kemudian untuk penentuan posisi menggunakan Global Positioning System (GPS) Geodetik yang dipasang pada kapal survei. Sedangkan perolehan data pasang surut dilakukan dengan alat Tide Master pada waktu yang sama dengan pengambilan data kedalaman.

\section{b. Lokasi Penelitian}

Penelitian ini dilaksanakan di Kepulauan Karimunjawa tepatnya di sekitar pelabuhan pada bulan Maret 2019. Pemilihan lokasi berdasarkan pertimbangan kondisi perairan yang dangkal karena keterbatasan sensor citra satelit dalam menembus objek perairan (Nuha dkk, 2019). Berikut adalah lokasi penelitian yang bersumber dari citra basemap (https://earthexplorer.usgs.gov/) di wilayah sekitar Pelabuhan Karimunjawa:

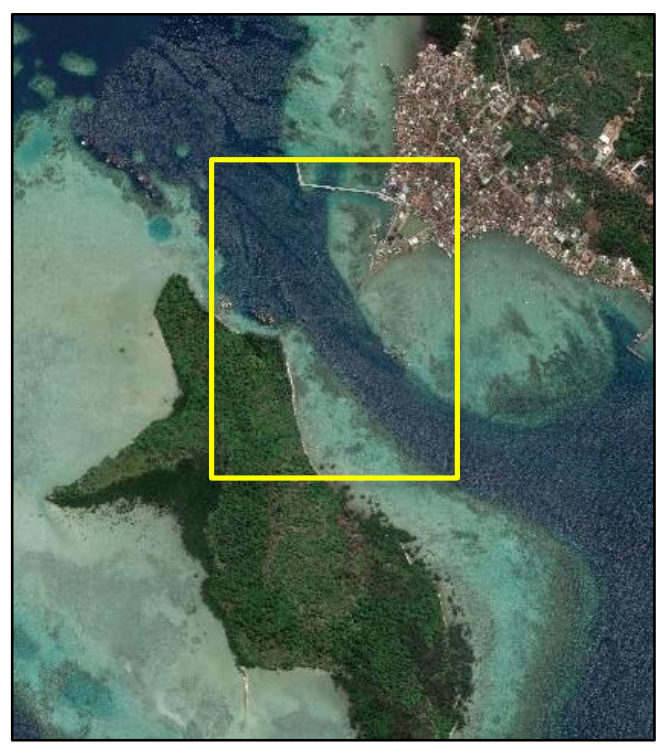

Gambar 2.1. Lokasi penelitian di sekitar pelabuhan Karimunjawa dengan citra Google Earth. Kotak kuning merupakan area penelitian

\section{Metodologi}

Bab ini menjelaskan mengenai metodologi penelitian dalam penelitian ini.

\section{a. Koreksi Sunglint (Kilatan Matahari)}

Koreksi Sunglint bertujuan untuk menghilangkan efek kilap matahari yang timbul akibat sudut datang sinar yang sama dengan sudut pantulannya sehingga menimbulkan bercak putih pada obyek perairan (Hochberg dkk, 2003; Hedley dkk, 2005). Syaiful dkk (2019) menyatakan bahwa koreksi ini bertujuan untuk menghilangkan efek gelombang perairan. Hochberg dkk (2003); Hedley dkk
(2005) telah menyempurnakan algoritma koreksi Sunglint sebagai berikut:

$$
R^{\prime} i=R i-b i(R N I R-M i n N I R)
$$

Dimana R'i adalah nilai kanal i setelah direduksi, Ri merupakan nilai kanal i awal, bi besarnya kemiringan regresi dan RNIR adalah nilai kanal serta Min NIR adalah nilai minimal kanal NIR.

\section{b. Metode Stumpf}

Estimasi kedalaman dalan penelitian ini menggunakan metode Stumpf (Stumpf dkk, 2003). Prinsip dari metode ini yaitu menggunakan ratio dua band dimana jika rasio meningkat maka hasil estimasi kedalaman juga akan meningkat. Jika kedalaman terus bertambah, band dengan tingkat penyerapan tinggi akan terus berkurang (Irwanto, 2018). Persamaan dari metode Stumpf adalah sebagai berikut:

$$
Z=m_{1}\left(\frac{\ln \left(n R_{w}\left(\lambda_{i}\right)\right)}{\ln \left(n R_{w}\left(\lambda_{j}\right)\right)}\right)-m_{0} \ldots \ldots \ldots \ldots \ldots
$$

Dimana $\mathrm{Z}$ merupakan kedalaman yang dicari, $\mathrm{m}_{1}$ adalah Koefisien kalibrasi, $\mathrm{R}_{\mathrm{w}}\left(\lambda_{\mathrm{ij}}\right)$ adalah Reflektansi perpanjangan gelombang, In adalah Konstanta, dan $\mathrm{m}_{0}$ adalah Koreksi kedalaman (0).

\section{c. Analisis Regresi}

Teknik SDB dengan metode Empiris yaitu menghubungkan nilai spektral citra dengan kedalaman terukur (Syaiful dkk, 2019). Untuk memperoleh nilai kedalaman dari setiap nilai reflektansi, maka digunakan persamaan Regresi Linear Sederhana. Hal tersebut bertujuan untuk melihat tingkat korelasi antara nilai spektral dengan kedalaman yang diketahui. Berikut Persamaan Regresi Linear Sederhana (3):

$$
Y=a X+b
$$

Dimana a adalah nilai slope, $\mathrm{b}$ adalah nilai intercept, dan X merupakan ratio reflektan band (Syaiful dkk, 2019).

\section{d. Uji Akurasi}

Persamaan yang digunakan dalam uji akurasi Root Mean Square Error (RMSE) adalah sebagai berikut (Walpole, 1968; Manessa dkk, 2017):

$$
R M S E=\sqrt{\frac{\sum_{t=1}^{n}(A t-F t)^{2}}{n}} \ldots \ldots \ldots(4)
$$

Dimana Ft adalah kedalaman terukur hasil survei dengan SBES, At adalah nilai estimasi kedalaman dari nilai piksel citra, dan $n$ adalah jumlah titik kedalaman terukur. 


\section{Hasil dan Pembahasan}

Bab ini menjelaskan mengenai hasil dan pembahasan yang dibagi menjadi tiga bagian yaitu preprocessing citra, pemrosesan data kedalaman dan pasang surut, serta pemrosesan citra yang meliputi analisis regresi dan uji akurasi.

\section{a. Preprocessing Citra}

Pertama yang perlu dilakukan adalah persiapan data yang digunakan. Citra Sentinel 2A diunduh melalui laman resmi https://earthexplorer.usgs.gov/. Kemudian dilakukan proses penggabungan band dalam satu data. Selanjutnya melakukan pemotongan citra (cropping) sesuai area penelitian yaitu sekitar pelabuhan Karimunjawa. Tahap selanjutnya yaitu koreksi

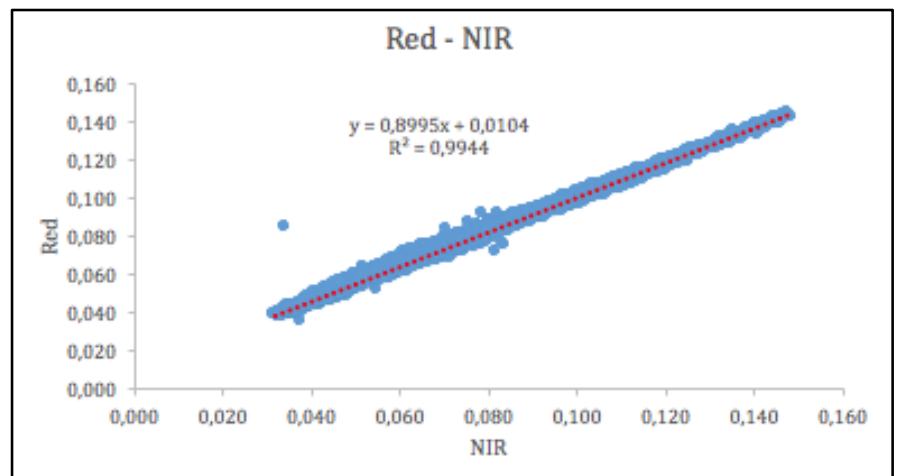

radiometrik pada citra Sentinel 2A yang bertujuan untuk memperbaiki nilai piksel dan meminimalkan distorsi dari efek atmosfer. Efek ini menyebabkan nilai pantulan sensor tidak mencerminkan obyek di lapangan kerena faktor hamburan maupun serapan (Danoedoro, 2012). Citra hasil unduhan memiliki nilai Digital Number (DN) yang besar sehingga tidak mencerminkan kondisi aslinya. Koreksi ini menggunakan persamaan $\mathrm{L}_{\lambda}=\mathrm{M}_{\mathrm{L}} \mathrm{Q}_{\text {cal }}+\mathrm{A}_{\mathrm{L}}$ dengan menggunakan nilai reflektan minimum dan maksimum (Akbari, 2016). Selanjutnya pada citra Worldview 3 dilakukan koreksi Sunglint. Koreksi ini dilakukan untuk meminimalkan efek kilap matahari yang terjadi di perairan (Syaiful dkk, 2019). Koreksi ini menggunakan band ratio Merah, Hijau, Biru dengan band NIR dimana nilai hasil regresi diaplikasikan pada setiap band. Berikut merupakan grafik linear koreksi Sunglint pada band Merah, Hijau, Biru dengan band NIR:

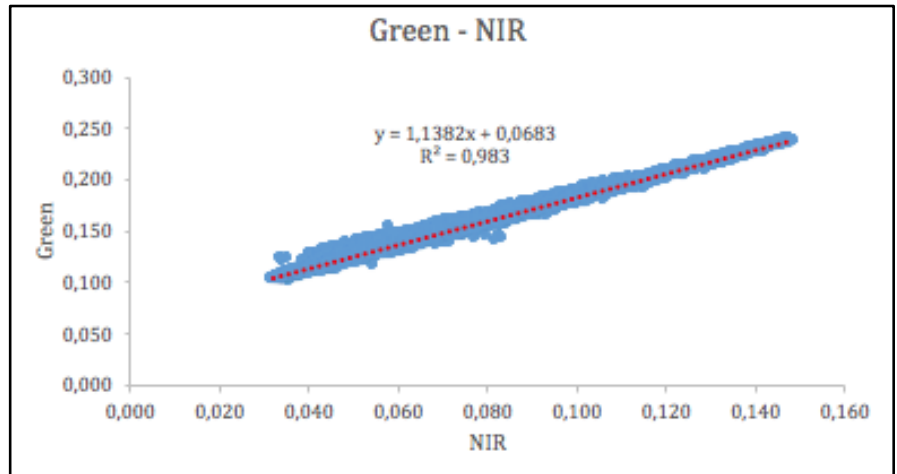

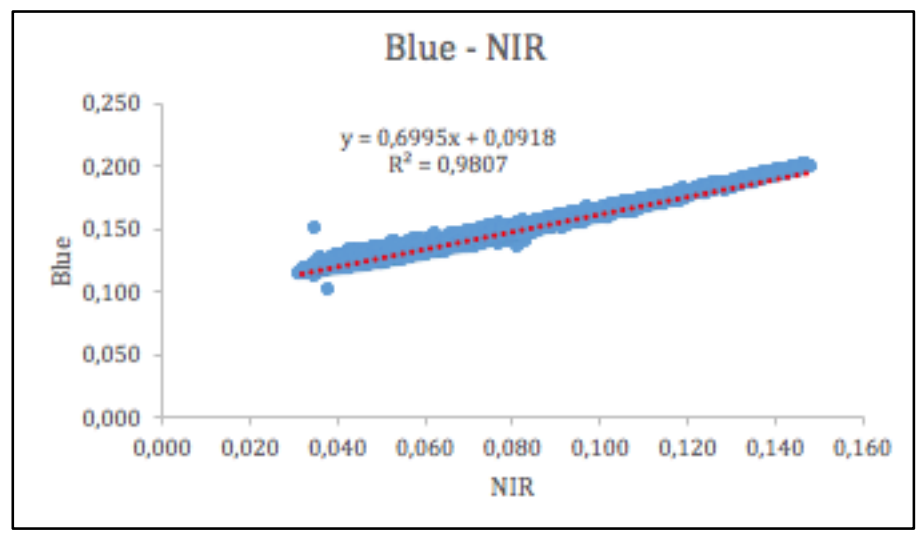

Gambar 4.1 Koreksi Sunglint citra Worldview 3 pada band Merah, Hijau dan Biru

b. Pemrosesan Data Kedalaman dan Pasang Surut

Data kedalaman diukur dengan menggunakan SBES Bathy-2010 SyQwest pada pada 20-23 Maret 2019. Sedangkan data pasang surut diukur dengan alat Tide Master yang bertujuan untuk koreksi agar data kedalaman terbebas dari pengaruh pasang surut. Posisi pemeruman menggunakan Global Navigation Satellite System (GNSS) metode absolut dengan tipe geodetik Trimble NET R9. Berikut merupakan hasil pemeruman yang ditampilkan pada citra Worldview 3 di sekitar Pelabuhan Karimunjawa, Jawa Tengah: 


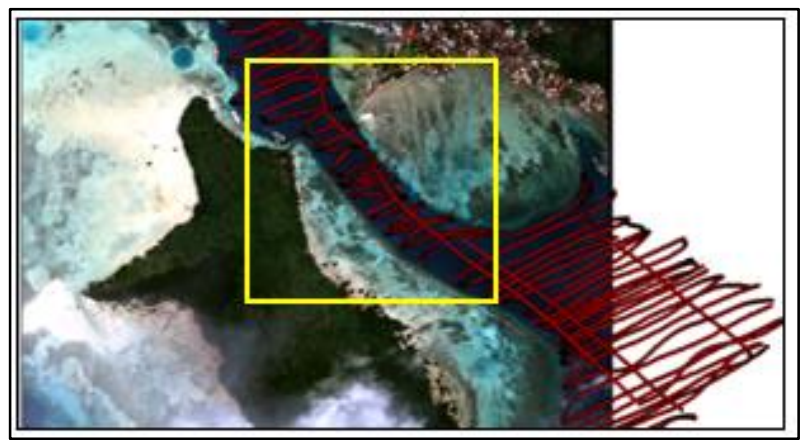

Gambar 4.2 Data pemeruman di sekitar Pelabuhan Karimunjawa

Penelitian ini menggunakan data kedalaman dengan rentang 0 sampai $25 \mathrm{~m}$ yang sudah terkoreksi pasang surut. Kedalaman tersebut dikelompokkan menjadi 5

\begin{tabular}{cc}
\multicolumn{2}{c}{ Tabel 4.1. Jumlah sampel kedalaman } \\
\hline Kedalaman (m) & Jumlah Sampel \\
\hline $0-5$ & 31 \\
\hline $5-10$ & 25 \\
\hline $10-15$ & 47 \\
\hline $15-20$ & 36 \\
\hline $20-25$ & 17 \\
\hline
\end{tabular}

\section{c. Pemrosesan Citra}

1. Analisis Regresi

Pertama yang dilakukan dalam estimasi kedalaman yaitu membuat sampling kedalaman dalam berbagai kelompok. Kemudian hasil sampling kedalaman diinput dan diproses sebagai vektor untuk data training. Kemudian data training yang sudah terbentuk dilakukan analisis regresi untuk melihat hubungan antara nilai kedalaman hasil estimasi dengan kedalaman terukur. Proses tersebut dilakukan pada kedua citra yang digunakan yaitu Worldview 3 dan Sentinel 2A. Dari hasil ektraksi kedalaman dengan metode Stumpf pada citra Worldview 3 dan Sentinel 2A digunakan untuk menentukan model kedalaman terbaik. Dari analisis regresi linear sederhana diperoleh bahwa model terbaik pada citra Worldview 3 yaitu dengan band ratio Hijau-Biru dengan nilai $\mathrm{y}=0,8847 \mathrm{x}+0,2204$ dan $\mathrm{R}^{2}$ sebesar 0,713 . Kemudian pada citra Sentinel 2A diperoleh model terbaik kelompok yaitu 0-5 m, 5-10 m, 10-15 m, 15-20 m, dan 20$25 \mathrm{~m}$. Jumlah setiap sampel kedalaman pada lokasi penelitian disajikan dalam berikut (Tabel 4.1): yaitu dengan band ratio Hijau-Biru dengan nilai $y=0,858 x$ $+0,3123$ dan $R^{2}$ sebesar 0,697.

\section{Uji Akurasi}

Estimasi kedalaman menggunakan model Stumpf yaitu dengan melihat nilai $\mathrm{R}^{2}$ paling tinggi pada band ratio yang digunakan. Penggunaan band ratio Hijau-Biru pada citra Worldview 3 dan Sentinel 2A didapatkan model terbaik pada citra Worldview 3 dengan nilai $y=0,8847 x+0,2204$ dan citra Sentinel 2A dengan nilai $y=0,858 x+0,3123$. Kedua persamaan tersebut diproses untuk mengetahui kedalaman dari estimasi nilai piksel setiap citra. Dari hasil uji RMSE, estimasi kedalaman terbaik dengan menggunakan metode Stumpf pada kedalaman 0-5 m pada citra Worldview 3 dan Sentinel 2A dengan nilai RMSE sebesar $1,5259 \mathrm{~m}$ dan 1,5576 m. Berikut merupakan informasi lengkap hasil RMSE pada citra Worldview 3 dan Sentinel 2A berbagai rentang kedalaman (Tabel 4.2):

Tabel 4.2. RMSE pada Citra Worldview 3 dan Sentinel 2A

\begin{tabular}{cc}
\hline Kedalaman (m) & Worldview 3 - RMSE (m) \\
\hline $0-5$ & 1,526 \\
\hline $5-10$ & 3,249 \\
\hline $10-15$ & 3,516 \\
\hline $15-20$ & 3,850 \\
\hline $20-25$ & 4,981 \\
\hline Kedalaman (m) & Sentinel 2A - RMSE (m) \\
\hline $0-5$ & 1,558 \\
\hline $5-10$ & 3,314 \\
\hline $10-15$ & 3,479 \\
\hline $15-20$ & 4,708 \\
\hline $20-25$ & 5,850 \\
\hline
\end{tabular}


Penggunaan satelit resolusi tinggi seperti Worldview 3 cenderung menghasilkan nilai RMSE yang lebih kecil dibandingkan dengan citra resolusi sedang. Hal ini dibuktikan dengan penelitian sebelumnya yang pernah dilakukan oleh Parente dkk (2018) menggunakan metode Stumpf. Penelitian tersebut menunjukkan bahwa korelasi antara nilai estimasi kedalaman dengan kedalaman terukur menunjukkan nilai $\mathrm{Z}=56.63 \mathrm{x}-77.87$ dan $\mathrm{R}^{2}$ sebesar 0.602 . Sedangkan penggunaan citra resolusi untuk estimasi kedalaman juga pernah dilakukan oleh Casal dkk (2020) dengan menggunakan citra Sentinel 2A dan metode Empiris. Penelitian tersebut menunjukkan bahwa prediksi kedalaman menghasilkan korelasi sebesar 27\% dan $14 \%$ pada metode Stumpf dan Lyzenga dengan prediksi spasial Kriging with an External Drift (KED). Kemudian penelitian Jaelani dkk (2019) menggunakan citra Pleiades-1B resolusi sedang menggunakan algoritma Van Hengel \& Spitzer dengan Geographically Weighted

\section{Kesimpulan}

Dari penelitian yang dilakukan di Kepulauan Karimunjawa, Jawa Tengah dapat disimpulkan bahwa model kedalaman terbaik pada citra Worldview 3 dan Sentinel $2 A$ yaitu dengan nilai $y=0,8847 x+0,2204$ dan $R^{2}$ sebesar 0,7135 dan $y=0,858 x+0,3123$ dan $R^{2}$ sebesar 0,6974 . Penggunaan band ratio Hijau-Biru pada citra Worldview 3 dan Sentinel 2A menghasilkan kedalaman terbaik pada rentang kedalaman 0-5 m yang ditunjukkan dengan nilai RMSE sebesar 1,526 m dan 1,558 m.

\section{Pernyataan Konflik Kepentingan}

Tulisan ini tidak ada konflik kepentingan apapun.

\section{Referensi}

Akbari, F. R. (2016). Evaluasi Pengaruh Koreksi Atmosferik Dalam Algoritma Untuk Perhitungan Total Suspended Solid Menggunakan Citra Satelit Landsat 8. Thesis. Institut Teknologi Sepuluh Nopember Surabaya.

Arya, Winarso, G., Sigit Kurniawan, E., \& Iwan Santoso, A. (2016). Evaluasi Akurasi Ekstraksi Kedalaman Laut Dengan Metode Lyzenga dan Modifikasinya Menggunakan Data Spot-7 Di Teluk Belangbelang Mamuju. Jurnal Ilmiah Geomatika, 2(1), 9-19. https://doi.org/10.37875/hidropilar.v2i1.39.

Bakara, J. (2014). Sistem Menejemen Data Citra Satelit Penginderaan Jauh Resolusi Tinggi Untuk Kebutuhan Nasional. Seminar Nasional Penginderaan Jauh, 751761.

Bobsaid, M. W., \& Jaelani, L. M. (2017). Studi Pemetaan Batimetri Perairan Dangkal Menggunakan Citra Satelit Landsat 8 dan Sentinel-2A (Studi Kasus: Perairan Pulau Poteran dan Gili Iyang, Madura). Jurnal Teknik ITS, 6, 564-569.
Regression (GWR) metode Empiris. Penelitian tersebut menunjukkan nilai NMAE sebesar 27,49\% dengan RMSE sebesar 2,46 m.

Penelitian serupa menggunakan Van Hengel \& Spitzer juga dilakukan oleh Setiawan dkk (2014) di Pulau Menjangan, Bali menggunakan citra Landsat Multitemporal. Penelitian tersebut menghasilkan RMSE sebesar 29\% dengan akurasi $80 \%$ dan $\mathrm{R}^{2}$ sebesar 0,439 tahun 1997. Kemudian pada tahun 2000 kesalahan ratarata sebesar $24 \%$ dengan akurasi $70 \%$ dan $\mathrm{R}^{2}$ sebesar 0,883 . Kemudian pada tahun 2003 estimasi kedalaman yang dihasilkan dengan RMSE sebesar $21 \%$, R ${ }^{2}$ sebesar 0,998 dan akurasi 80\%. Dari penjelasan beberapa penelitian diatas menunjukkan bahwa citra satelit resolusi tinggi menghasilkan nilai RMSE yang cenderung lebih kecil dibandingkan dengan citra resolusi sedang.

https://doi.org/10.12962/j23373539.v6i2.24182.

Casal, G., Harris, P., Monteys, X., Hedley, J., Cahalane, C., \& McCarthy, T. (2020). Understanding satellite-derived bathymetry using Sentinel 2 imagery and spatial prediction models. GIScience and Remote Sensing, $57(3)$, 271-286. https://doi.org/10.1080/15481603.2019.1685198.

Danoedoro, P. (2012). Pengantar Pengindraan Jauh Digital. In Benedicta Rini W (Ed.), Penerbit ANDI (1st ed.). Penerbit ANDI.

Dhani Irwanto. (2018). Perkiraan Batimetri Perairan Dangkal Menggunakan Citra Landsat 8. Prosiding Seminar Nasional Kelautan Dan Perikanan, IV, 1-12.

Digital Globe. (2014). Worldview 3. http://worldview3.digitalglobe.com/. (Diakses 8 November 2020).

Digital Globe. (2016). Atmospheric Compensation. (Diakses 9 November 2020).

Gao, J. (2009). Bathymetric mapping by means of remote sensing: Methods, accuracy and limitations. Progress in Physical Geography, 33(1), 103-116. https://doi.org/10.1177/0309133309105657.

Hedley, J. D., Harborne, A. R., \& Mumby, P. J. (2005). Simple and robust removal of sun glint for mapping shallowwater benthos. International Journal of Remote Sensing. https://doi.org/10.1080/01431160500034086.

Hochberg, E. J., Andréfouët, S., \& Tyler, M. R. (2003). Sea surface correction of high spatial resolution ikonos images to improve bottom mapping in near-shore environments. IEEE Transactions on Geoscience and Remote Sensing, 41, 1724-1729. https://doi.org/10.1109/TGRS.2003.815408.

Jaelani, L. M., \& Putri, K. (2019). Analisis Kemampuan Citra Satelit Pleiades-1B Dalam Mengestimasi Kedalaman Perairan Gili Iyang Dengan Menerapkan Geographically Weighted Regression (Gwr). Geoid, 
14(2),

$28-34$ https://doi.org/10.12962/j24423998.v14i2.3877.

Kuncoro Teguh Setiawan, Takahiro Osawa, I. W. N. (2014). Aplikasi Algoritma Van Hengel Dan Spitzer Untuk Ekstraksi Informasi Batimetri Menggunakan Data Landsat. Seminar Nasional Penginderaan Jauh, 222230.

Lyzenga, D. R. (1978). Passive remote sensing techniques for mapping water depth and bottom features. Applied https://doi.org/10.1364/ao.17.000379.

Manessa, M. D. M., Haidar, M., Hartuti, M., \& Kresnawati, D. K. (2017). Determination Of The Best Methodology For Bathymetry Mapping Using Spot 6 Imagery: A Study of 12 Empirical Algorithms. International Journal of Remote Sensing and Earth Sciences (IJReSES), 4(2), 127-136. https://doi.org/10.30536/j.ijreses.2017.v14.a2827.

Muhammad Ulin Nuha, Abdul Basith, W. A. (2019). Optimalisasi Parameter Analitis Ekstraksi Kedalaman Laut dengan Citra Satelit Resolusi Tinggi Pada Zona Laut Dangkal (Studi Kasus: Perairan Pelabuhan Karimunjawa). Thesis. Universitas Gadjah Mada.

Pajar Pajrin. (2018). Algoritma Zona Penetrasi Kedalaman untuk Pemetaan Batimetri Perairan Dangkal Menggunakan Citra Satelit Sentinel-2A. Skripsi. Universitas Hassanudin.

Parente, C., \& Pepe, M. (2018). Bathymetry from worldview-3 satellite data using radiometric band ratio. Acta Polytechnica, 58(2), 109-117. https://doi.org/10.14311/AP.2018.58.0109.

Pusat Hidrografi dan Oseanografi Angkatan Laut. (2016). Sejarah Pushidrosal. TNI AL. https://www.pushidrosal.id/assets/filemanager/pdf /SEJARAH_PUSAT_HIDROGRAFI_DAN_OSE.pdf. (Diakses 12 November 2020).

Santosa, P. B. (2016). Evaluation of satellite image correction methods caused by differential terrain illumination. Jurnal Forum Geografi. Vol. 30, No. 1 (2016). doi:10.23917/forgeo.v30i1.1768

Satellite Imaging Corporation. (2017). Sentinel-2A (10m) Satellite

Sensor.

https://www.satimagingcorp.com/satellitesensors/other-satellite-sensors/sentinel-

2a/\#: :text=Sentinel-2A Satellite Sensor Specifications\&text=MSI covering 13 spectral bands,(three atmospheric correction bands). (Diakses 1 November 2020).

Satellite Imaging Corporation. (2020). Worldview-3 Band Spesifications. https://www.satimagingcorp.com/. (Diakses 11 November 2020).

Stumpf, R. P., Holderied, K., Robinson, J. a, Feldman, G., \& Kuring, N. (2003). Mapping water depths in clear water from space. Proceedings of the 13th Biennial Coastal Zone Conference Baltimore, MD July 13-17, 2003.

Surya N. Syaiful, Muhammad Helmi dan Sugeng Widada, Rikha Widiaratih, P. S., \& Suryoputro, A. A. D. (2019). Analisis Digital Citra Satelit Worldview-2 untuk Ekstraksi Kedalaman Perairan Laut di Sebagian Perairan Pulau Parang, Kepulauan Karimunjawa, Provinsi Jawa Tengah. Indonesian Journal of Oceanography, Vol 01 No:, 1-8.

United States Geological Survey. (2015). USGS EROS Archive - Sentinel-2. Earth Resources Observation and Science (EROS) Center. https://www.usgs.gov/centers/eros/science/usgseros-archive-sentinel-2?qt-

science_center_objects $=0 \# q$ t-science_center_objects. (Diakses 3 November 2020).

Walpole, R. E. (1968). Introduction to Statistics. Macmillan. Wicaksono, P. (2015). Perbandingan Akurasi Metode Band Tunggal dan Band Rasio dalam Pemetaan Batimetri Pada Laut Dangkal Optis. Simposium Nasional Sains Geoinformasi IV, 802-810. 